Case Report

\title{
A Case Report: Lobular Carcinoma In Situ in a Male Patient with Subsequent Invasive Ductal Carcinoma Identified on Screening Breast MRI
}

\author{
Linda Kao, Yekaterina Bulkin, Susan Fineberg, Leslie Montgomery, Tova Koenigsberg ${ }^{\bowtie}$ \\ Montefiore Medical Center, Greene Medical Arts Pavilion, 3400 Bainbridge Avenue. Bronx, NY 10467, USA
}

Corresponding author: Phone: (718) 920-5400; Fax: (718) 324-1156; tkoenigs@montefiore.org

( ) Ivyspring International Publisher. This is an open-access article distributed under the terms of the Creative Commons License (http://creativecommons.org/ licenses/by-nc-nd/3.0/). Reproduction is permitted for personal, noncommercial use, provided that the article is in whole, unmodified, and properly cited.

Received: 2012.01.14; Accepted: 2012.03.02; Published: 2012.05.22

\begin{abstract}
Lobular carcinoma in situ is a form of in situ neoplasia that develops within the terminal lobules of the breast. It is an extremely rare finding in males due to the lack of lobular development in the male breast. The authors herein report an unusual case of incidentally discovered lobular carcinoma in situ in a male patient with recurrent bilateral gynecomastia who was subsequently diagnosed with invasive ductal carcinoma of the left breast. The pathology of lobular carcinoma in situ in a male as well as screening MRI surveillance of male patients at high risk for breast cancer are discussed, emphasizing the importance of screening and imaging follow up in men who are at high risk for breast cancer.
\end{abstract}

Key words: Lobular carcinoma in situ, male, breast cancer, MRI, screening and imaging

\section{Introduction}

Lobular carcinoma in situ (LCIS) is a form of in situ neoplasia that develops within the terminal lobules of the breast. It is extremely rare in males due to the lack of lobular development in the male breast. Furthermore, there is scarce data on the utility of screening MRI for male patients who are known to have high risk lesions.

We herein report a rare case of LCIS in a male breast discovered incidentally on pathologic analysis of the breast tissue, which had been removed during breast reduction surgery for gynecomastia. Invasive ductal carcinoma developed in the ipsilateral breast two years later, as was detected on screening MRI.

\section{Case Report}

The patient is a 55-year-old African American male who reported a brief history of anabolic steroid use and no family history of breast cancer. The patient had a history of multiple surgical procedures for recurrent gynecomastia over the course of many years.
The patient presented to our institution for bilateral breast reduction for cosmetic purposes. Pathologic evaluation demonstrated a few foci of LCIS within the left breast along with atypical duct cell hyperplasia in a background of gynecomastia. Due to the highly unusual finding of LCIS in this male patient, genetic analysis was performed and the male $X Y$ genotype was confirmed.

The patient was subsequently referred to our breast imaging center for a screening bilateral breast MRI. This demonstrated mild diffuse background enhancement bilaterally without suspicious enhancing signal abnormalities in either breast. Screening annual breast MRI was recommended in view of his highly unusual diagnosis of LCIS.

Screening MRI of both breasts performed 15 months later demonstrated interval development of a $1.1 \mathrm{~cm}$ enhancing ill-defined mass at the 1 o'clock axis of the left breast (Figure 1). A corresponding solid hypoechoic mass with angulated margins was seen on 
targeted left breast ultrasound (Figure 2). Mammography demonstrated heterogeneously dense breast tissue with post surgical changes bilaterally. No dominant mass or suspicious clustered microcalcifications were identified in either breast (Figure 3). U1trasound guided core biopsy yielded moderately differentiated invasive ductal carcinoma.
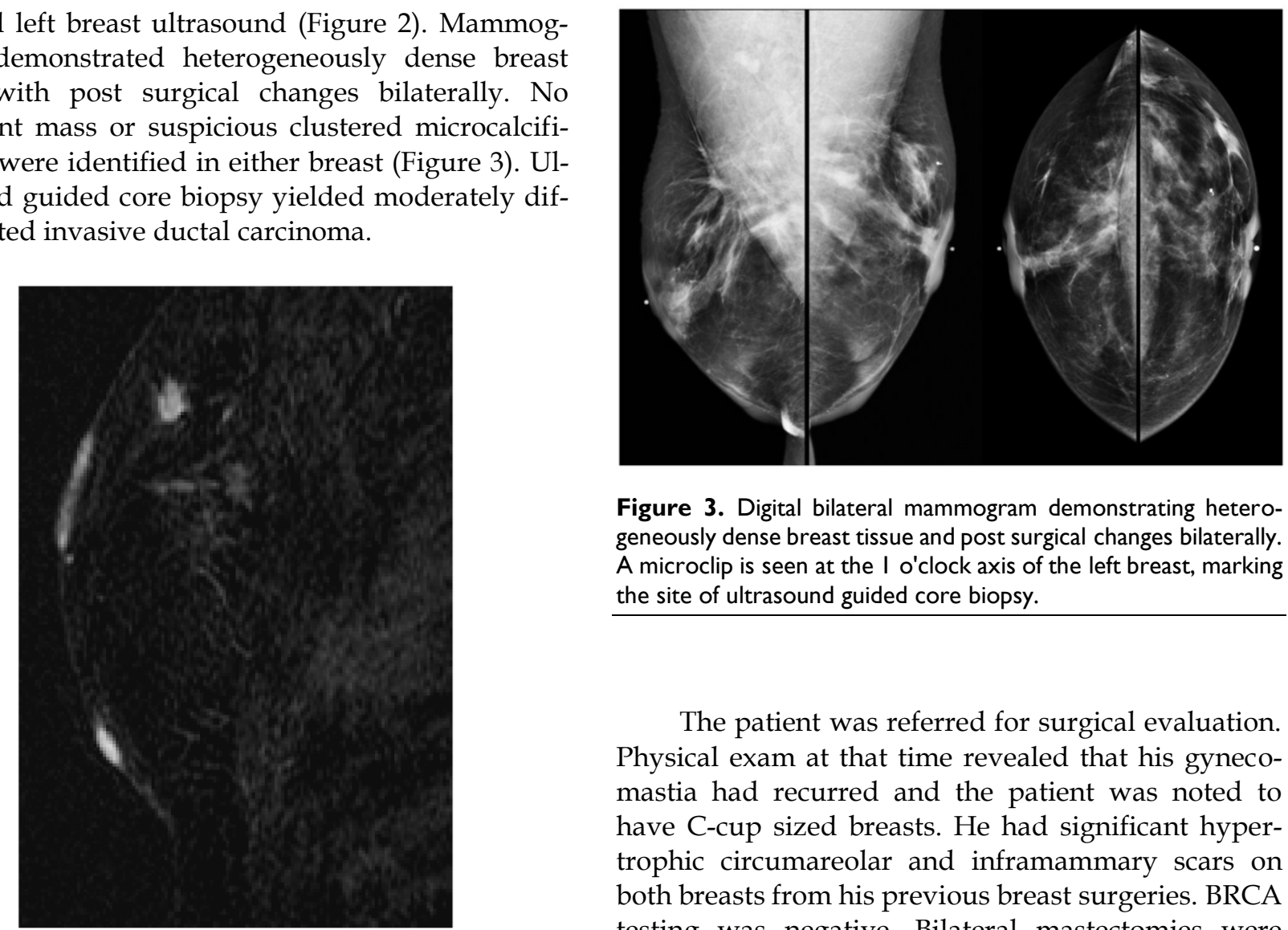

Figure 3. Digital bilateral mammogram demonstrating heterogeneously dense breast tissue and post surgical changes bilaterally. A microclip is seen at the I o'clock axis of the left breast, marking the site of ultrasound guided core biopsy.

Figure I. MR image demonstrating a I.I cm suspicious enhancing mass at the left breast I o'clock axis for which targeted ultrasound was recommended.

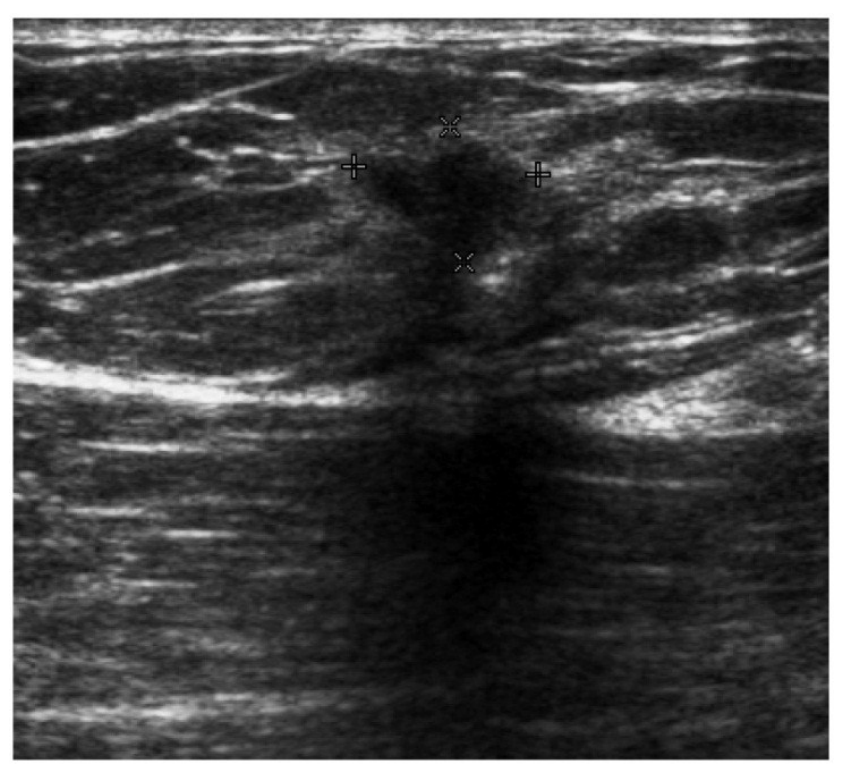

Figure 2. Targeted ultrasound of the left breast demonstrating a solid hypoechoic lesion at the I o'clock axis which corresponded to the enhancing lesion on the MRI. 
fusely positive for both estrogen and progesterone receptors and negative for Her-2/Neu. Lobular carphase gynecomastia. Sentinel lymph nodes were cinoma in situ was present bilaterally as was florid negative.

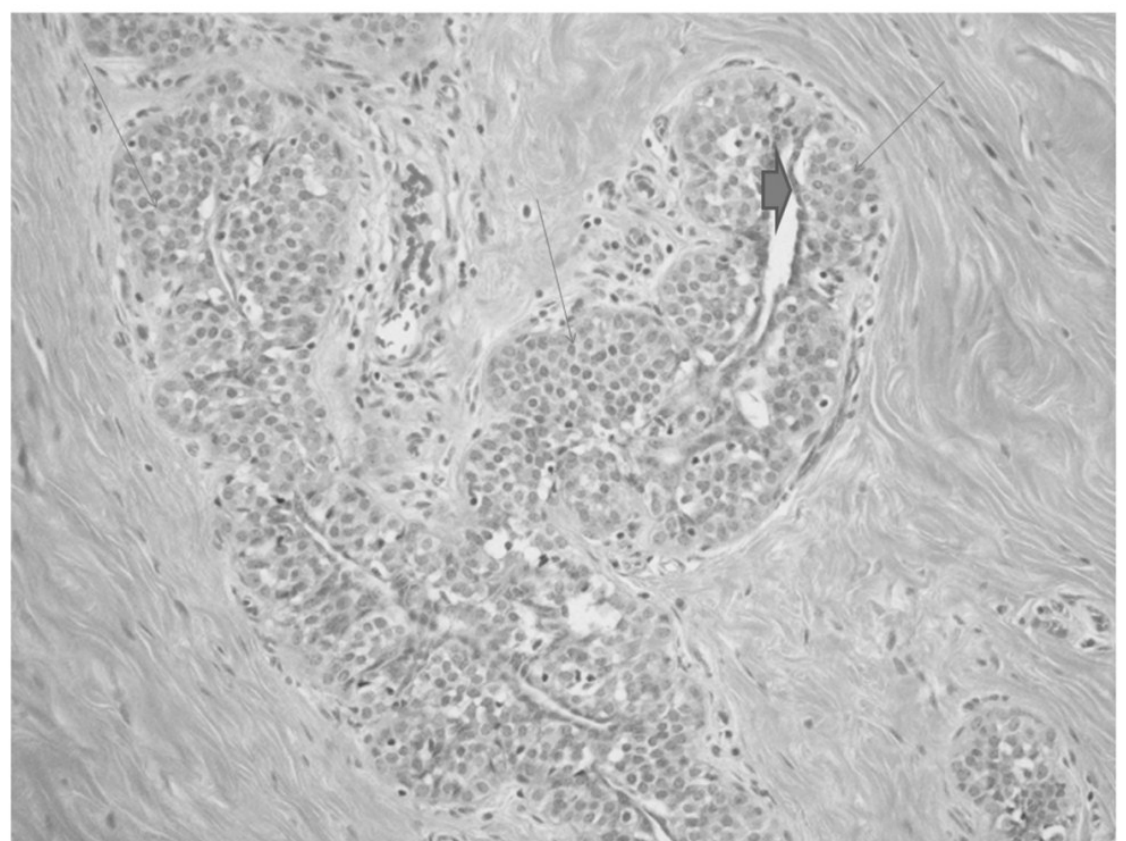

Figure 4. Monotonous small cells of lobular carcinoma in situ (thin arrows) show pagetoid extension along ducts with undermining of normal ductal epithelium (thick arrow).

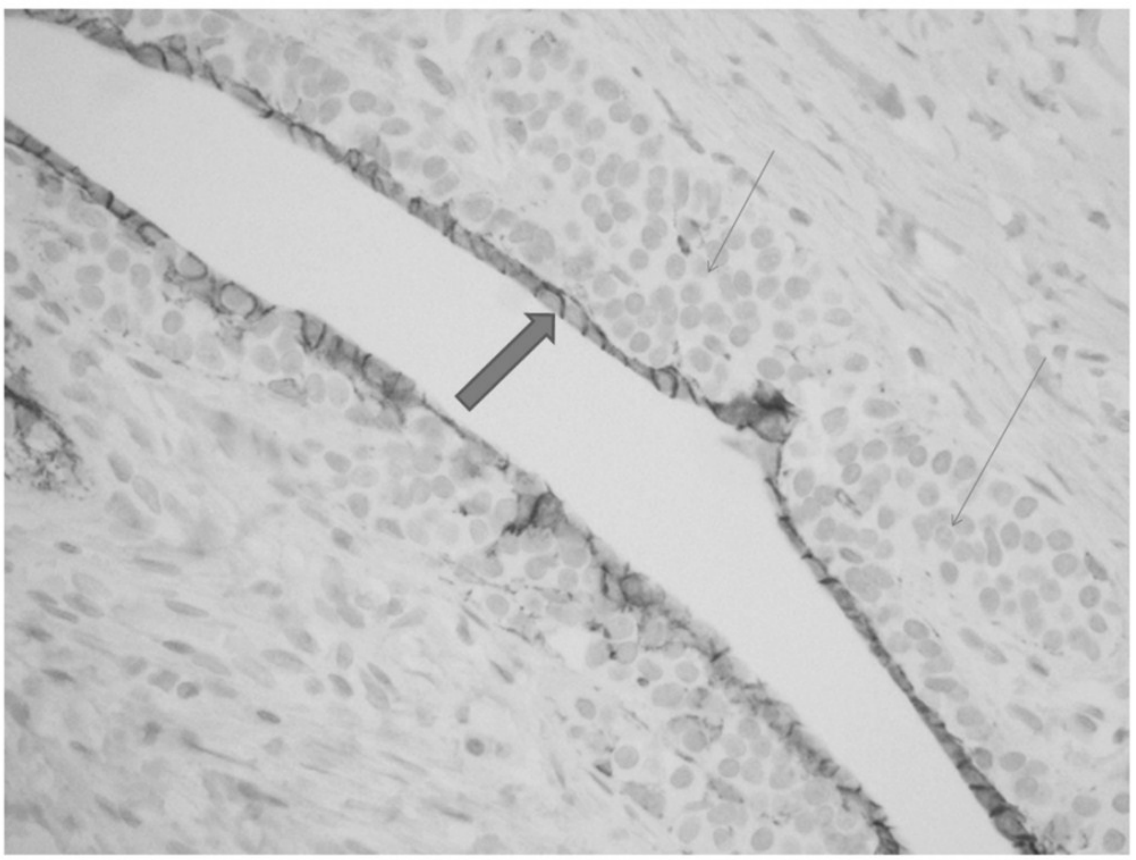

Figure 5. E-cadherin immunostain shows absence of staining in cells of lobular carcinoma in situ (thin arrows) with positive staining in residual benign ductal cells (thick arrow). 


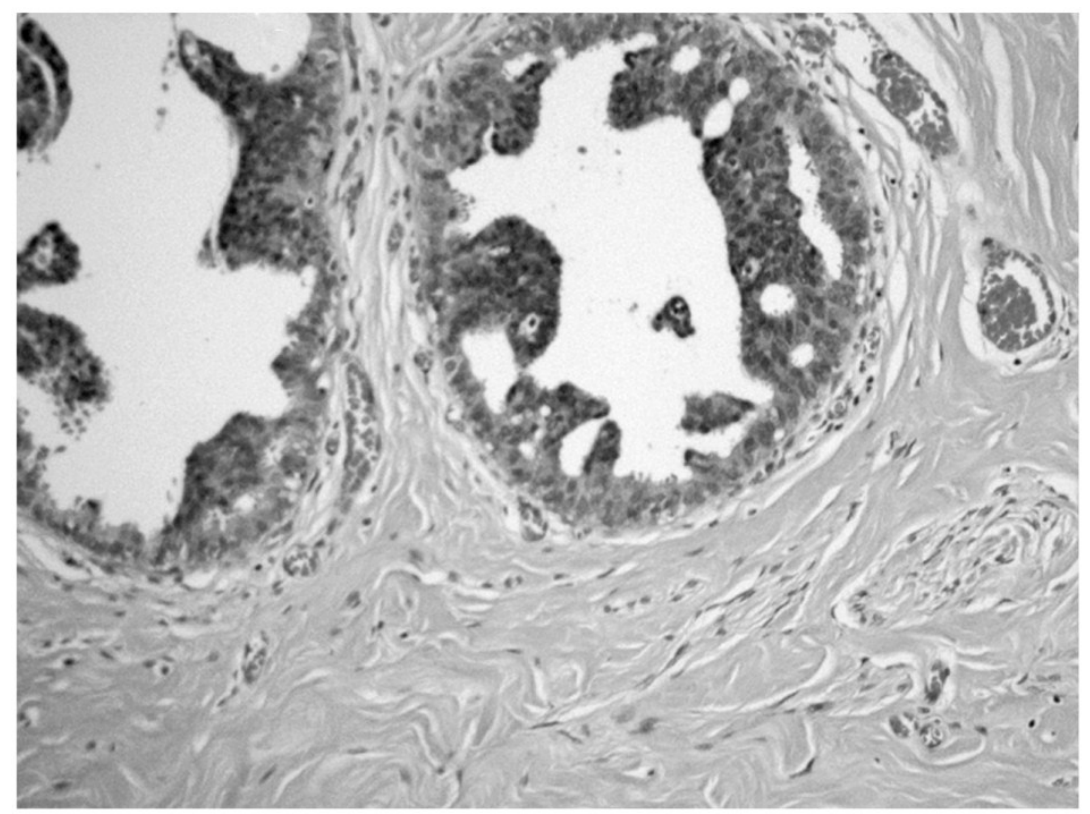

Figure 6. Atypical ductal hyperplasia showing hyperchromatic cells with micropapillary type.

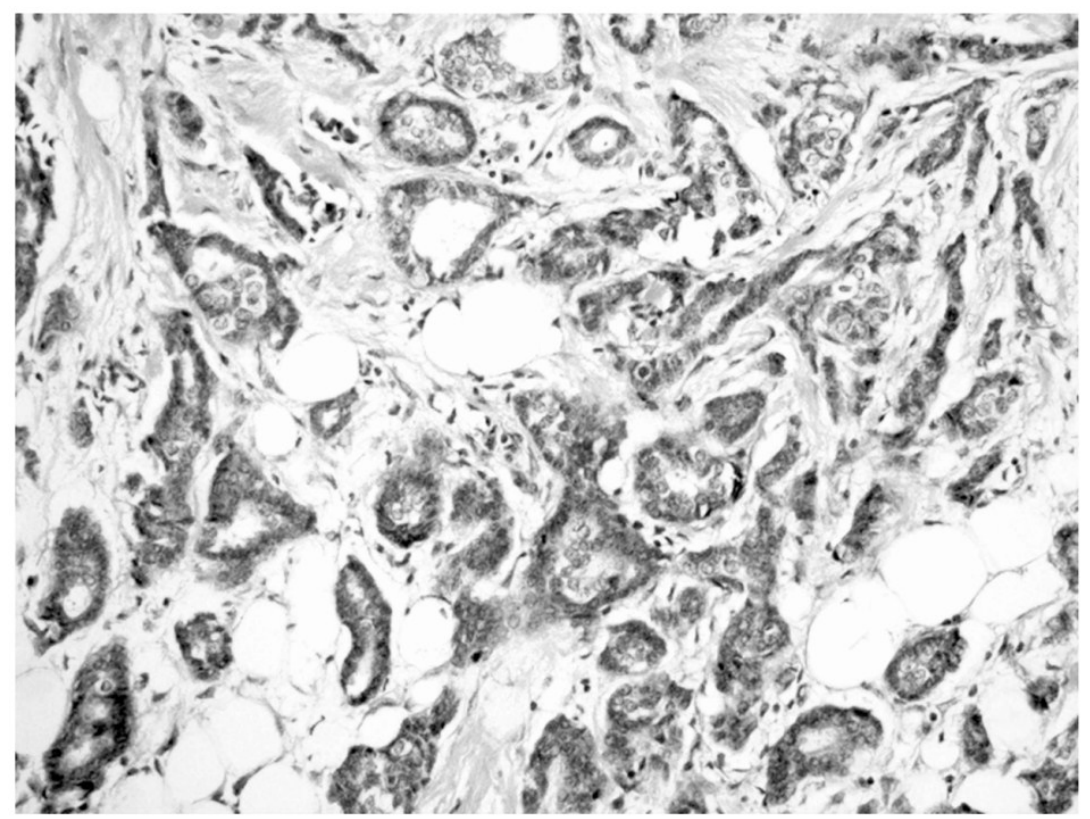

Figure 7. Invasive ductal carcinoma showing a mixture of infiltrating tubules and cords of cells.

\section{Discussion}

Breast carcinoma in men is an uncommon disease, representing approximately $1 \%$ of all breast cancers and $1 \%$ of all malignancies in men; although based on current statistics, the incidence of male breast cancer is increasing $(1,2)$. While the etiology of male breast cancer is uncertain, risk factors include genetic predisposition, prior radiation exposure, alterations of the estrogen-testosterone ratio, and oc- cupational hazards (3). To date, there is no evidence linking gynecomastia with male breast cancer $(4,5)$.

Male breast cancers are predominantly of ductal origin due to the lack of terminal lobules within the male breast. As a result, LCIS and infiltrating lobular carcinoma are extremely unusual in male patients (6). Nance et al reported the first case of LCIS in a phenotypic and apparently genotypic male in 1989 in association with a large infiltrating lobular carcinoma (7); and in fact, only a limited number of cases of in- 
filtrating lobular carcinoma of the male breast have been reported (8).

Over the past decade, there has been an increase in the number of imaging studies performed in male patients. These are largely performed in patients who present with complaints of a breast lump and/or breast pain. Although there are no standardized protocols in evaluating the male breast, mammography is usually the initial study and is followed by ultrasound as needed (9). Occasionally, MRI may be obtained for further evaluation, and it has been shown that the diagnostic criteria used in the evaluation of the female breast may be applied to the male breast as well (10). However, there are no guidelines regarding screening mammography in asymptomatic men at any age due to the rarity of male breast cancer. In the absence of screening, most male patients present with clinical symptoms and more advanced disease (11). Current National Comprehensive Cancer Network guidelines for men with BRCA mutations recommend consideration of baseline mammography followed by annual mammography in those men who are shown to have gynecomastia on the baseline study (12).

The role of screening MRI even in female patients with LCIS is not well established despite the fact that LCIS is known to represent a high risk marker lesion. In fact, lifetime risk estimates for patients with incidentally diagnosed LCIS range from 10 to $20 \%$, imparting a significant lifetime risk for the development of invasive ductal or lobular carcinoma in either breast $(13,14)$. In 2007, a retrospective study evaluated screening MRI in asymptomatic female patients with LCIS, demonstrating a small increase in early cancer detection (15). Subsequently, the 2007 American Cancer Society guidelines for screening breast MRI advised that there was insufficient evidence to recommend for or against screening MRI in patients with a known diagnosis of LCIS and only recommended annual screening breast MRI for patients with a lifetime risk of greater than 20-25\% (16). The $2009 \mathrm{Na}-$ tional Comprehensive Cancer Network guidelines, however, advised consideration of annual breast MR imaging as an adjunct to mammography and clinical examination in these patients (17). More recently, two additional retrospective studies specifically studied screening breast MRI in asymptomatic female patients with LCIS and concluded that screening breast MRI is a useful adjunctive tool to mammography in this high risk population $(18,19)$. As such, one may extrapolate this information to males with a known diagnosis of LCIS and recommend screening MRI, as was done in this case.

This case report is, to the best of our knowledge, the first reported case of a genotypic and phenotypic male patient without a BRCA mutation, who was found to have incidental LCIS which was unrelated to a lobular carcinoma. In addition, this is the first reported case of a male patient with LCIS to be screened with annual MRI surveillance and in whom the MRI detected a mammographically occult stage I invasive ductal carcinoma. This case highlights the importance of imaging management and the potential for an improved prognosis in men who are at high risk for breast cancer.

\section{Competing Interests}

The authors have declared that no competing interest exists.

\section{References}

1. Giordano SH, Cohen DS, Buzdar AU, Perkins G, Hortobagyl GN. Breast carcinoma in men: a population based study. Cancer. 2004;101:51-57.

2. Pant K, Dutta U. Understanding and management of male breast cancer: a critical review. Med Oncol. 2008;25:294-298.

3. Johansen Taber KA, Morisy LR, Osbahr AJ, Dickinson BD. Male breast cancer: risk factors, diagnosis, and management (review). Oncology Reports. 2010;24:1115-1120.

4. Fentiman IS, Fourquet A, Hortobagyi GN. Male breast cancer. Lancet. 2006;367:595-604.

5. Cardenosa G. Breast imaging; 1st ed Chapter 9, The male breast; p299-312. Philadelphia: Lippincott Williams \& Wilkins. 2004.

6. Giordano SH, Cohen DS, Buzdar AU, Perkins G, Hortobagyl GN. Breast carcinoma in men: a population based study. Cancer. 2004;101:51-57.

7. Nance KV, Reddick RL. In situ and infiltrating lobular carcinoma of the male breast. Human Pathology. 1989;20:1220-1222.

8. Mariolis-Sapsakos T, Theodoropoulos G, Flessas II, Orfanos F, Orfanos $\mathrm{N}$, Konstadinou E, et al. Lobular breast cancer in men: case report and review of the literature. Onkologie. 2010;33:698-700.

9. Iuanow E, Kettler M, Slanetz PJ. Spectrum of disease in the male breast. AIR. 2011;196:247-259.

10. Morakkabati-Spitz H, Schild HH, Leutner CC, von Falkenhausen M, Lutterbey G, Kuhl CK. Dynamic contrast-enhanced breast MR imaging in men: preliminary results. Radiology. 2006;238:438-445.

11. Giordano SH, Cohen DS, Buzdar AU, Perkins G, Hortobagyl GN. Breast carcinoma in men: a population based study. Cancer. 2004;101:51-57.

12. Korde LA, Zujewski J, Kamin L, Giordano S, et al. Multidisciplinary meeting on male breast cancer: summary and research recommendations. Journal of Clinical Oncology. 2010;28:2114-2122.

13. Simpson PT, Gale T, Fulfor LG, et al. Pathology of atypical lobular hyperplasia and lobular carcinoma in situ. Breast Cancer Res. 2003;5:258-262.

14. Arpino G, Laucirica R, Elledge RM. Premalignant and in situ breast disease: biology and clinical implications. Ann intern Med. 2005;143(6):446-457.

15. Port ER, Park A, Borgen PI, Morris E, Montgomery LL. Results of MRI screening for breast cancer in high-risk patients with LCIS and atypical hyperplasia. Annals of Surgical Oncolog. 2007;14:1051-1057.

16. Saslow D, Boetes C, Burke E, et al. American Cancer Society guidelines for breast screening with MRI as an adjunct to mammography. CA Cancer J Clin. 2007;57(2):75-89.

17. Bevers $\mathrm{TB}$, Anderson BO, Bonaccio $\mathrm{E}$, et al. NCCN clinical practice guidelines in oncology: breast cancer screening and diagnosis. J Natl Compr Canc Netw. 2009;7(10):1060-1096.

18. Friedlander LC, Orel Roth S, Gavenonis SC. Results of MR imaging screening for breast cancer in high-risk patients with lobular carcinoma in situ. Radiology. 2011; doi:10.1148/radiol.11103516.

19. Sung JS, Malak SF, Punam B, et al. Screening breast MR imaging in women with a history of lobular carcinoma in situ. Radiology. 2011; doi:10.1148/radiol.11110091. 